\title{
HPV Genotypes of Senegalese Women Attending Radiotherapy
}

\author{
M. Soumboundou 1,2,3,4*, I. Thiam ${ }^{5}$, K. Doh ${ }^{5}$, M. M. Dieng, ${ }^{6}$ C. Dial ${ }^{7}$, C. Malesys ${ }^{2}$, \\ P. M. Guaye ${ }^{6}$, A. Z. Thioune ${ }^{4}$, A. Dem ${ }^{6}$, M. Diarra ${ }^{1}$, C. R. Lafrasse ${ }^{2}$ \\ ${ }^{1}$ Laboratoire Physique Pharmaceutique, FMPO Université Cheikh Anta Diop de Dakar, Sénégal \\ ${ }^{2}$ Laboratoire Radiobiologie Cellulaire et moléCulaire de Lyon 1, Université Claude Bernard, Lyon Contry, France \\ ${ }^{3}$ Service Biophysique Médical UFR, Santé Thiès, Sénégal \\ ${ }^{4}$ Hopital Pour Enfants de Diamniadio, Dakar, Sénégal \\ ${ }^{5}$ Laboratoire d'anatomie et de cytologie pathologiques de l'Hôpital Aristide Le Dantec, Dakar, Sénégal \\ ${ }^{6}$ Service cancérologie et radiothérapie Institut Joliot Curie de l'Hôpital Aristide Le Dantec, Dakar, Sénégal \\ ${ }^{7}$ Laboratoire d'anatomie et de cytologie pathologiques de l'Hôpital Général de Grand Yoff, Dakar, Sénégal \\ Email: *soumboun@hotmail.com
}

How to cite this paper: Soumboundou, M., Thiam, I., Doh, K., Dieng, M.M., Dial,C., Malesys, C., Guaye, P.M., Thioune, A.Z., Dem, A., Diarra, M. and Lafrasse, C.R. (2018) HPV Genotypes of Senegalese Women Attending Radiotherapy. Open Journal of Biophysics, 8, 85-94.

https://doi.org/10.4236/ojbiphy.2018.82007

Received: February 13, 2018

Accepted: April 27, 2018

Published: April 30, 2018

Copyright (C) 2018 by authors and Scientific Research Publishing Inc. This work is licensed under the Creative Commons Attribution International License (CC BY 4.0).

http://creativecommons.org/licenses/by/4.0/

\begin{abstract}
Objectives: This work was carried out in order to determine the profile of different HPV genotypes in a population of women attending radiotherapy (RT). Material and Methods: This is a retrospective study. Sixty paraffin blocks were chosen by simple random method upon 1015 blocks of cervix cancer diagnosed in Senegal's public hospitals laboratories of anatomopathology. The strains of HPV genotyping were done with polymerase chain reaction (PCR) multiplex using primers MY09-MY11, GP5+ and GP6+. Results: Among the sixty examined blocks, DNA extraction was unsatisfactory in three cases. All women were infected with HPV high risk (HR). The different HPV genotypes isolated were HPV 16 (49/96\%), 18 (8/16\%), 35 (7/14\%), $45(4 / 8 \%)$, and $58(2 / 4 \%)$. It was a single infection in 36 cases $(70,60 \%)$, co-infection in 11 cases $(21,60 \%)$ and a multi-infection in 4 cases $(7,80 \%)$. Conclusion: The prevalence of HPV found in our series is comparable to that found in the world. To complete this study, a large population of Senegalese patients with uterine cervix cancer (CC) and HPV genotype, is needed to determine if HPV genotypes could be considered as a prognostic marker in patients with uterine CC after RT.
\end{abstract}

\section{Keywords}

HPV, Cervix Cancer, Genotype, Radiotherapy, Senegal 


\section{Introduction}

Human papillomavirus (HPV) is responsible for more than 493,000 cases of cervical cancer worldwide each year and about 274,000 deaths worldwide [1].

Highly oncogenic human papillomavirus (HPV) infections are responsible for $7.7 \%$ of cancers in developing countries, mainly cervical cancer. The incidence of this cancer is emerging steadily increasing in sub-Saharan Africa, with more than 75,000 new cases and close to 50,000 deaths a year, a toll further increased by HIV infection. According to the World Health Organization, cervical cancer will kill more than 443,000 women per year worldwide by 2030 , nearly $90 \%$ of them in sub-Saharan Africa [2].

Persistent high-risk HPV (HR-HPV) infection is involved in more than 90\% of cervical cancer cases and has been identified as a causal factor in development of cancer [3]. Generally, HPV16 and HPV18 cause about 70\% of cervical cancer cases [4].

In Senegal, cervical cancer (CC) is the first cancer in terms of frequency and mortality among women [5]. This is a public health problem hence the urgency of preventive measures, including vaccination [6]. A preliminary study in four regions of Senegal in 936 asymptomatic women showed a prevalence of $18.1 \%$ of high-risk HPV infection (HPV-HR). HPVs-HR types found in order of frequency were HPV31 (25.9\%), HPV52 (19.4\%), HPV45 (13.5\%), HPV16 (13\%) and HPV51 (10.6\%) [5].

The strong correlation between the presence of HPV and the development of cervical cancer has enabled the research lead to the development of two vaccines. However, these vaccines only cover a few HPV genotypes, others have not been the subject of vaccine development, but seem to be a problem, demonstrated by various studies in Africa [7].

The primary treatment strategy for uterine CC consists of surgery or radiotherapy (RT). Surgery is usually reserved for early-stage disease and small lesions including stage IA, IB1, and selected IIA1 diseases [8]. Based on the results of randomized clinical trials, chemoradiotherapy (CCRT) has become the main treatment for stage IB2 to IVA disease [9]. YOKO et al. study suggests that HPV negative patients with cervical cancer have a significantly poorer prognosis after radiotherapy, and HPV status may be used as a marker to optimize the treatment of patients with this type of cancer [10].

Senegal is a developing country that has difficulty in getting his medical platform with radiotherapy and molecular biology.

This work was carried out in order to determine the profile of different HPV genotypes in a population of women attending radiotherapy (RT), in order to integrate them after into understanding the response to radiotherapy.

\section{Materials and Methods}

\section{Study samples}

A retrospective series of 60 FFPE primary cervix cancer cases, diagnosed be- 
tween 2015 and 2016, were retrieved from the archives of the Pathology department of the National Cancer Institute of Dakar, Senegal. All the cases had been characterized for the presence of HPV-DNA by MPG.

\section{DNA extraction}

Depending on the size of the lesion, 1-3 $\mu \mathrm{m}$ FFPE sections were obtained. The utmost care was taken during the cutting protocol in order to avoid contamination [11]. Sections were deparaffinized with $1 \mathrm{ml}$ of xylene at $56^{\circ} \mathrm{C}$ for $5 \mathrm{~min}$. The xylene was removed by washing with $1 \mathrm{ml}$ of absolute ethanol. Tissue lysis was obtained by overnight incubation at $56^{\circ} \mathrm{C}$ in $180 \mathrm{ml}$ of buffer with $20 \mathrm{ml}$ of proteinase $\mathrm{K}$ (Qiagen), followed by $1 \mathrm{~h}$ incubation at $90^{\circ} \mathrm{C}$. Details on the extraction and amplification of HPV DNA and HPV genotyping by MPG are provided in.

\section{Multiplex HPV Genotyping (MPG)}

Multiplex BSGP5+/GP6+ PCR-MPG was carried out with primers reported previously by Schmitt et al., 2008 [12]. The assay used nine sense primers BSGP5+ at $200 \mathrm{nM}$ and 3 antisense primers 5'-biotinylated-BSGP6+ at $400 \mathrm{nM}$ to amplify a $\sim 150 \mathrm{bp}$ fragment of the viral L1 ORF, as well as two additional primers (MS3/MS10) at $300 \mathrm{nM}$ to amplify the $\mathcal{B}$-globin gene, which was used as DNA integrity control [13]. The multiplex Luminex hybridization assay enabled the detection of 27 mucosal HPV-genotypes: 1) high risk (HR)-HPV types: 16, $18,31,33,35,39,45,51,52,56,58,59,66,68 ; 2)$ possibly HR-HPV types: 26,53 , $67,70,73,82$; low risk (LR)-HPV types: $6,11,30,43,44$ and 69 . In addition, the $\beta$-globin product was amplified in each sample.

Oligonucleotide probes with an amino group at the 5' end for each of the 27 HPV types were coupled to carboxylated beads using the carbodiimide procedure described by Schmitt et al., 2006 [14]. For each combination of probes and beads we used 2.5 million carboxylated beads in $25 \mu \mathrm{L}$ of $0.1 \mathrm{M} 2$-(N-morpholino) ethanesulfonic acid (MES), pH 4.5, with $200 \mu \mathrm{g}$ of

$\mathrm{N}$-(3-dimethylaminopropyl)-N-ethylcarbodiimide (EDC) and $400 \mathrm{pmol}$ of probe, the mixture was incubated in the dark under stirring for 30 minutes, the addition of EDC and incubation was repeated once, then the beads were washed with $0.5 \mathrm{ml}$ of $0.2 \mathrm{~g} / \mathrm{L}$ of Tween 20 and once with $0.5 \mathrm{ml}$ of $1.0 \mathrm{~g} / \mathrm{L}$ SDS. Finally, they were stored at $4^{\circ} \mathrm{C}$ in TE solution. Hybridization was performed in 96 well plates with $10 \mu \mathrm{L}$ of PCR product in $33 \mu \mathrm{L}$ of hybridization solution $(0.15 \mathrm{M}$ of tetramethylammonium chloride (TMAC), $75 \mathrm{mM}$ Tris-HCl, $6 \mathrm{mM}$ EDTA, 1.5 g/L Sarkosyl, $\mathrm{pH}$ 8.0) to which 2000 bead-coupled probes were added. This mixture was incubated at $95^{\circ} \mathrm{C}$ for 10 minutes and immediately placed on ice for 2 minutes, then it was placed at $41^{\circ} \mathrm{C}$ for 30 minutes under stirring, then the samples were transferred to a wash plate with filter bottom (Millipore, Bedford, MA) pre-equilibrated with blocking solution (PBS with 0.2 g/L Tween-20 and 2.0 M TMAC), and washed with blocking solution to eliminate non-hybridized DNA in a vacuum wash station (Millipore). Subsequently, biotinylated PCR products were stained with streptavidin-R-phycoerythrin conjugate (Molecular Probes) diluted 1:1600 in 2.0 M TMAC, 75 mM Tris-HCl, 6 mM EDTA, 1.5 g/L 
Sarkosyl, $1.0 \mathrm{~g} / \mathrm{L}$ casein, $\mathrm{pH} 8.0$ and incubated 20 minutes at room temperature with shaking. After washing three times with blocking solution, the beads were analyzed in a Luminex 100 reader (Luminex Corp.), which uses two lasers, one that recognizes the bead set by the internal bead color and another to quantify the reporter fluorescence on the bead. The results were expressed in median fluorescence intensities (MIF) of 100 beads per sample [12] [13] [14].

\section{Statistical analysis}

SPSS 20.0 software was used for data analysis. Only a descriptive analysis was performed. The genotyping results were analyzed using Excel. For each probe, MFI values in reactions with no PCR product added to the hybridization mixture were considered background values. Reactions with net MFI values above 5 were defined as positive reactions.

\section{Results}

\section{Study Patient Characteristics}

Of the 60 enrolled patients (Mean age+/-S.D.: 48.63+/-10.77 years), 98.3\% had squamous cell carcinoma and $1.7 \%$ had adenocarcinoma. Of the 60 blocks examined, DNA extraction was unsatisfactory in six cases. Fifty one patients were positive for the HPV high risk infection. By accumulating the genotypes of HPV found, we found in all five HPV high risks (Figure 1).

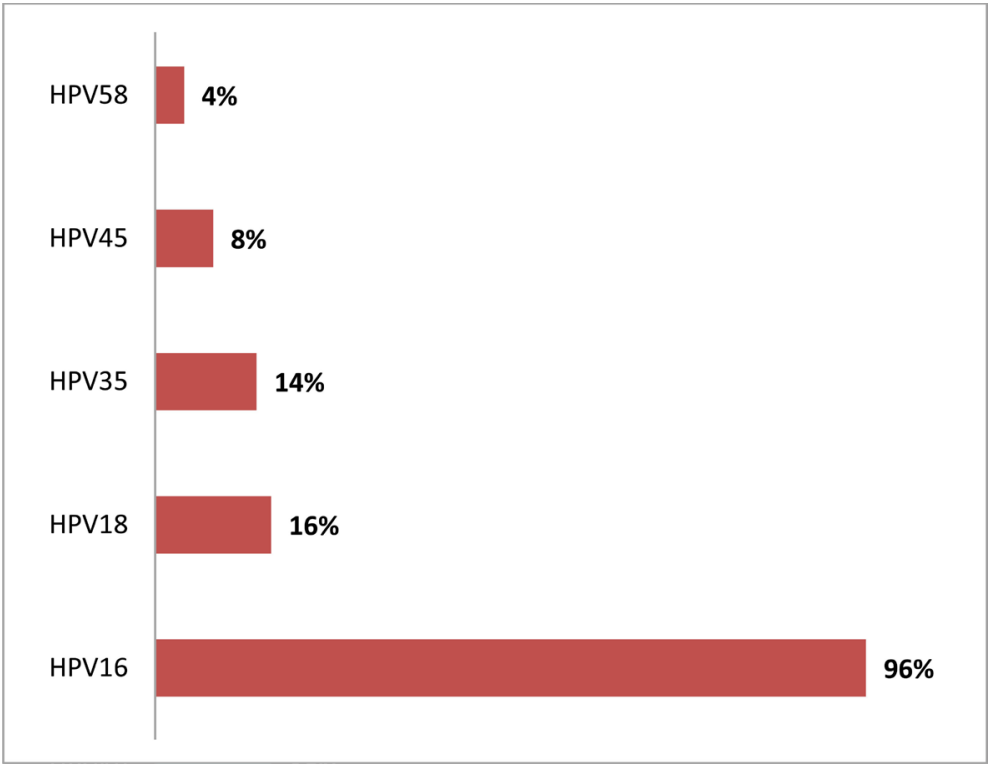

Figure 1. Frequencies of HPV in study population.

\begin{tabular}{cccc}
\hline TYPE VIRUS & Frequencies & Total & $\%$ \\
\hline HPV16 & 49 & 51 & $96 \%$ \\
HPV18 & 8 & 51 & $16 \%$ \\
HPV35 & 7 & 51 & $14 \%$ \\
HPV45 & 4 & 51 & $8 \%$ \\
HPV58 & 2 & 51 & $4 \%$ \\
\hline
\end{tabular}




\section{HPV Genotype Distribution among HPV-Positive cervix cancer}

The analysis showed that among the 54 women, fifty one (94\%) were infected with at least one type of oncogenic risk HPV of which 36 had a single HPV type infection, 11 had co-infection, and rest 4 had infection with more than two types of HPV (Table 1).

In our study we isolated few cases of multiple infections: $30 \%$ of women had two or more types of HPV. In contrast, 70\% of women had one type of HPV infection. The most common type of infections found in this study was respectively HPV-16 (67\%) and HPV-35 (4\%). Co-infection with HPV 16 and 18 was found (8\%) (Table 2).

\section{HPV Prevalence by Age}

Analysis of the prevalence of HR-HPVs by age showed an overwhelming presence of these viruses in all age group, with greater positivity in patients over 40 years old (73\%). The hpv-16 showed much frequency rates, with a maximum in the group more than 40 years old (98\%). The age does not predict significantly about HPV type (Table 3).

\section{Discussion}

The present study is the first to show the distribution of human papillomavirus genotypes before RT in Senegalese patients with uterine Cervix Cancer (CC). The majority of patients in the study were HPV-positive, with a high proportion of HPV 16, 58, 18, 52. Although the number of patients in the present study was small, the results were consistent with previous reports regarding global incidence of HPV genotypes in CC [15]. De Sanjose et al. found that HPV 16 and 18

Table 1. Type of infection.

\begin{tabular}{cccc}
\hline TYPE INFECTION & Frequencies & Percent & P-VALUE \\
\hline Single Infection & 36 & $70 \%$ & \\
Multiple Infection & 15 & $30 \%$ & 0,005 \\
TOTAL & $\mathbf{5 1}$ & $\mathbf{1 0 0 \%}$ & \\
\hline
\end{tabular}

Table 2. Distribution of women according to the status HPV infection single or in multiple.

\begin{tabular}{ccc}
\hline HPV-HR type & N & Percent (\%) \\
\hline 16 & 34 & $67 \%$ \\
35 & 2 & $4 \%$ \\
$16+18$ & 4 & $8 \%$ \\
$16+35$ & 3 & $6 \%$ \\
$16+45$ & 4 & $8 \%$ \\
$16+18+35$ & 2 & $4 \%$ \\
$16+18+58$ & 2 & $4 \%$ \\
TOTAL & 51 & $100 \%$ \\
\hline
\end{tabular}


Table 3. Prevalence by age of HPV-HR.

\begin{tabular}{|c|c|c|c|c|c|c|c|}
\hline \multirow{2}{*}{ HPV-HR Positif } & \multicolumn{2}{|c|}{ Age $<40$} & \multicolumn{2}{|c|}{ Age $>40$} & \multirow{2}{*}{$\mathbf{N}$} & \multirow{2}{*}{$\%$} & \multirow{2}{*}{ P-value } \\
\hline & $\mathbf{n}$ & $\%$ & $\mathbf{n}$ & $\%$ & & & \\
\hline 16 & 10 & $29 \%$ & 24 & $71 \%$ & 34 & $67 \%$ & \multirow{8}{*}{0.48} \\
\hline 35 & 1 & $50 \%$ & 1 & $50 \%$ & 2 & $4 \%$ & \\
\hline $16+18$ & 2 & $50 \%$ & 2 & $50 \%$ & 4 & $8 \%$ & \\
\hline $16+35$ & 0 & $0 \%$ & 3 & $100 \%$ & 3 & $6 \%$ & \\
\hline $16+45$ & 0 & $0 \%$ & 4 & $100 \%$ & 4 & $8 \%$ & \\
\hline $16+18+35$ & 1 & $50 \%$ & 1 & $50 \%$ & 2 & $4 \%$ & \\
\hline $16+18+58$ & 0 & $0 \%$ & 2 & $100 \%$ & 2 & $4 \%$ & \\
\hline TOTAL & 14 & $27 \%$ & 37 & $73 \%$ & 51 & $100 \%$ & \\
\hline
\end{tabular}

were the most common genotypes for uterine CC in the world [15]. However, Salehi-Vaziri et al. reported that the most common HPV genotypes in Iranian women were HPV 16 and 53 [16]. García Muentes et al. reported that the most common HPV genotypes in Ecuadorian women were HPV 16 and HPV 33 [17].

A fairly important patient rate (30\%) in the study was positive for several HPV types (Table 1). A recent study in a Colombian population found $62.5 \%$ of multiple infections among HPV-infected women by conventional PCR [18]. The frequency of multiple infections found in our study as compared to this may reflect that multiple infections are a common phenomenon.

Our results collaborate with those of Muñoz and colleagues who reported frequencies of $91.9 \%$ and $8.1 \%$ for single and multiple infections, respectively [19].

Radiotherapy induces high levels of DNA damage in tumor cells with the aim to promote apoptosis. The addition of cisplatin to radiotherapy increased anti-tumor effects, and has been shown to improve therapy outcome in cervical cancer [20]. DNA DSBs, as induced by radiotherapy, can be repaired by two fundamentally distinct pathways: non-homologous end-joining (NHEJ) and homologous recombination (HR) [21].

HPV infection has been linked to altered DNA repair through various mechanisms. Importantly, expression of HPV oncogenes appears to negatively impact the ability to repair DNA, pointing at an increased sensitivity of HPV-positive cells, such as most cervical cancer cells, for genotoxic agents [22].

Others studies results indicate that patients with high initial HPV titers could be favorably treated with radiotherapy alone. Chemotherapy in HPV positive tumors could be ineffective since in vitro studies have been reported these to be chemoresistant, while HPV negative cells were found to be chemosensitive [23] [24].

In our study, the positive HPV rate is above $80 \%$. Given this HPV positivity rate in our series, it is important to discuss the association chemotherapy in the management of this cancer in our country. 
Although the involvement of HPV in the development of cervical cancer has been firmly established, however, its prognostic significance in patients presenting with HPV positive and HPV negative cervical cancer has yielded conflicting results. A good correlation between presence of HPV and outcomes has been demonstrated by several workers [25] [26] [27] [28].

Recently, Wang and al. have illustrated with a large population (1010 patients) and long-term follow-up (median, 78 months) that the presence of HPV alpha-7 species or HPV negativity (high-risk group) was significantly associated with a poorer outcome of cervical cancer patients undergoing RT. Further, some authors demonstrated that HPV16-related alpha-9 species significantly lowers the risk of cervical cancer-related death and recurrence/metastasis than the alpha-7 species, which was consistent with a previous study in patients undergoing primary radiotherapy [29] [30].

Thus, the HPV genotypes should be considered as a biomolecular marker for cervical cancer. As a reminder, all HPV found in our study belong to these two groups alpha-9 $(16,52,33,31$, and 58) and alpha- $7(18,39,59,68$, and 45$)$ with predominance of HPV 16 . So, we can consider that the rate of tumor recurrence observed after radiotherapy by the team of DEM et al. in the same center may be due to other mechanisms of radioresistance [31].

Another study showed that HPV16 positivity was significantly associated with improved prognosis in the whole series of cervical cancer and also in subgroup receiving primary RT/CCRT [32]. Given the number of HPV 16 in our series, we can expect a very good response from our patients treated with exclusive radiotherapy.

In vitro studies have revealed significant differences in biological behaviors between HPV types. For example, HPV16 is associated with a higher level of tumor apoptosis than HPV18, affording one possible explanation for more radiosensitive cervical cancer with HPV16 [33].

Given the much lower prevalence of HPV18 in cervical cancer than HPV16, independent studies with large sample size are needed to assess the impact of HPV18 on patients' prognosis.

About the multiple infections, some considered that older women with different new sexual partners might be tended to infect with multiple HPV [34] [35].

Furthermore, since HPV16, the most oncogenic HPV known, was detected in all CC cases, the presence of other HPV types in the same lesions may represent concomitant infections. It remains to be determined to which extent each virus contributes to the prognostic in radiotherapy.

One of the limitations of our study was that we could not include the response after radiotherapy. Because the machine broke down for the duration of the study. In addition, there was a phenomenon of loss of sight of patients.

\section{Conclusion}

In conclusion, the results of the present study further evidence for the notion 
that cervical HPV infection, also with multiple types, is widespread. However, further large population studies on the usefulness HPV genotype information in Senegalese patients with uterine CC are needed to determine if HPV genotypes could be considered as a prognostic marker in patients with uterine CC after RT.

\section{Acknowledgements}

This study was supported by the Laboraty of Radiological Cellular and Molecular (Lyon Sud, France).

\section{References}

[1] Chauhan, S.C., Jaggi, M., Bell, M.C., Verma, M. and Kumar, D. (2009) Epidemiology of Human Papilloma Virus (HPV) in Cervical Mucosa. Methods Mol Bio, 471, 439-456. https://doi.org/10.1007/978-1-59745-416-2_22

[2] Mboumba Bouassa, R.S., Prazuck, T., Lethu, T., Meye, J.F. and Bélec, L. (2017) Cervical Cancer in Sub-Saharan Africa: An Emerging and Preventable Disease Associated with Oncogenic Human Papillomavirus. Médecine et Santé Tropicales, 27, 16-22.

[3] Dunne, E.F. and Park, I.U. (2013) HPV and HPV-Associated Diseases. Infectious Disease Clinics of North America, 27, 765-778.

https://doi.org/10.1016/j.idc.2013.09.001

[4] Durst, M., Gissmann, L., Ikenberg, H. and zurHausen, H. (1983) A Papillomavirus DNA from a Cervical Carcinoma and Its Prevalence in Cancer Biopsy Samples from Different Geographic Regions. Proceedings of the National Academy of Sciences of the United States of America, 80, 3812-3815.

https://doi.org/10.1073/pnas.80.12.3812

[5] Mbaye, E.H.S., Gheit, T., Dem, A., McKay-Chopin, S., Toure-Kane, N.C., Mboup, S., Tommasino, M., Sylla, B.S. and Boye, C.S.B. (2014) Human Papillomavirus Infection in Women in Four Regions of Senegal. Journal of Medical Virology, 86, 248-256. https://doi.org/10.1002/jmv.23719

[6] Gomez, T. and Juana, L.S. (2007) Human Papillomavirus Infection and Cervical Cancer Pathogenesis and Epidemiology. In: Méndez Vilas, A., Ed., Communicating Current Research and Educational Topics and Trends in Applied Microbiology, Vol. 1, 680-688.

[7] Fukuchi, E., Sawaya, G.F., Chirenje, M., Magure, T., Tuveson, J., Ma, Y., Shiboski, et al. (2009) Cervical Human Papillomavirus Incidence and Persistence in a Cohort of HIV-Negative Women in Zimbabwe. Sexually Transmitted Diseases, 36, 305-311.

[8] American College of Obstetricians and Gynecologists (2002) ACOG Practice Bulletin. Diagnosis and Treatment of Cervical Carcinomas. American College of Obstetricians and Gynecologists. International Journal of Gynaecoly Obstetics, 78, 79-91.

[9] Gaffney, D.K., Erickson-Wittmann, B.A., Jhingran, A., Mayr, N.A., Puthawala, A.A., Moore, D., Rao, G.G., Small Jr., W., Varia, M.A., Wolfson, A.H., et al. (2011) ACR Appropriateness Criteria ${ }^{\circledR}$ on Advanced Cervical Cancer Expert Panel on Radiation Oncology-Gynecology. International Journal of Radiation Oncology Biology Physics, 81, 609-614. https://doi.org/10.1016/j.ijrobp.2010.11.005

[10] Yoko, H., Satoshi, S., Kenji, N., Mitsuharu, S. and Takeo, O. (2002) Human Papilloma Virus (HPV) DNA Associated with Prognosis of Cervical Cancer after Radiotherapy. International Journal of Radiation Oncology Biology Physics, 52, 1345-1351. https://doi.org/10.1016/S0360-3016(01)02796-1 
[11] Dona, M.G., Ronchetti, L., Giuliani, M., Carosi, M., Rollo, F., Congiu, M., et al. (2013) Performance of the Linear Array HPV Genotyping Test on Paired Cytological and Formalin-Fixed, Paraffin-Embedded Cervical Samples. The Journal of Molecular Diagnostics, 15, 373-379. https://doi.org/10.1016/j.jmoldx.2013.01.002

[12] Schmitt, M., Dondog, B., Waterboer, T. and Pawlita, M. (2008) Homogeneous Amplification of Genital Human Alpha Papillomaviruses by PCR Using Novel Broad-Spectrum GP5+ and GP6+ Primers. Journal of Clinical Microbiology, 46, 1050-1059. https://doi.org/10.1128/JCM.02227-07

[13] Dunbar, S.A., Vander Zee, C.A., Oliver, K.G., Karem, K.L. and Jacobson, J.W. (2003) Quantitative, Multiplexed Detection of Bacterial Pathogens: DNA and Protein Applications of the Luminex LabMAP ${ }^{\mathrm{TM}}$ System. Journal of Microbiological Methods, 53, 245-252. https://doi.org/10.1016/S0167-7012(03)00028-9

[14] Schmitt, M., Bravo, I.G., Snijders, P.J.F., Gissmann, L., Pawlita, M. and Waterboer, T. (2006) Bead-Based Multiplex Genotyping of Human Papillomaviruses. Journal of Clinical Microbiology, 44, 504-512. https://doi.org/10.1128/JCM.44.2.504-512.2006

[15] De Sanjose, S., Quint, W.G., Alemany, L., Geraets, D.T., Klaustermeier, J.E., Lloveras, B., Tous, S., Felix, A., Bravo, L.E., Shin, H.R., et al. (2010) Human Papillomavirus Genotype Attribution in Invasive Cervical Cancer: A Retrospective Cross-Sectional Worldwide Study. The Lancet Oncology, 11, 1048-1056. https://doi.org/10.1016/S1470-2045(10)70230-8

[16] Salehi-Vaziri, M., Sadeghi, F., Hashemi, F.S., Haeri, H., Bokharaei-Salim, F., Monavari, S.H. and Keyvani, H. (2016) Distribution of Human Papillomavirus Genotypes in Iranian Women According to the Severity of the Cervical Lesion. Iranian Red Crescent Medical Journal, 18, e24458. https://doi.org/10.5812/ircmj.24458

[17] García Muentes, G.D., García Rodríguez, L.K., Burgos Galarraga, R.I., Almeida Carpio, F. and Ruiz Cabezas, J.C. (2016) Genotypes Distribution of Human Papillomavirus in Cervical Samples of Ecuadorian Women. Revista Brasileira de Epidemiologia, 19, 160-166. https://doi.org/10.1590/1980-5497201600010014

[18] Soto-De Leon, S., Camargo, M., Sanchez, R., et al. (2011) Distribution Patterns of Infection with Multiple Types of Human Papillomaviruses and Their Association with Risk Factors. PLOS ONE, 6, e14705. https://doi.org/10.1371/journal.pone.0014705

[19] Muñoz, N., Bosch, F.X., de San Jose, S., et al. (2003) Epidemiologic Classification of Human Papillomavirus Types Associated with Cervical Cancer. The New England Journal of Medicine, 348, 518-527. https://doi.org/10.1056/NEJMoa021641

[20] Rose, P.G., Bundy, B.N., Watkins, E.B., Thigpen, J.T., Deppe, G., Maiman, M.A., et al. (1999) Concurrent Cisplatin-Based Radiotherapy and Chemotherapy for Locally Advanced Cervical Cancer. The New England Journal of Medicine, 340, 1144-1153. https://doi.org/10.1056/NEJM199904153401502

[21] Ma, Y., Lu, H., Tippin, B., Goodman, M.F., Shimazaki, N., Koiwai, O., et al. (2004) A Biochemically Defined System for Mammalian Nonhomologous DNA End Joining. Molecular Cell, 16, 701-713. https://doi.org/10.1016/j.molcel.2004.11.017

[22] Wieringa, H.W., van der Zee, A.G.J., de Vries, E.G.E. and van Vugt, M.A.T.M. (2016) Breaking the DNA Damage Response to Improve Cervical Cancer Treatment. Cancer Treatment Reviews, 42, 30-40. https://doi.org/10.1016/j.ctrv.2015.11.008

[23] Saxena, A., Yashar, C., Taylor, D.D. and Gercel-Taylor, C. (2005) Cellular Response to Chemotherapy and Radiation in Cervical Cancer. American Journal of Obstetrics 
\& Gynecology, 192, 1399-1403. https://doi.org/10.1016/j.ajog.2004.12.045

[24] Datta, N.R., Kumar, P., Singh, S. and Gupta, D. (2006) Does Pretreatment Human Papillomavirus (HPV) Titers Predict Radiation Response and Survival Outcomes in Cancer Cervix?-A Pilot Study. Gynecologic Oncology, 103, 100-105. https://doi.org/10.1016/j.ygyno.2006.01.058

[25] Huang, L.W., Chao, S.L. and Hwang, J.L. (2004) Human Papillomavirus-31-Relatedtypes Predict Better Survival in Cervical Carcinoma. Cancer, 100, 327-334. https://doi.org/10.1002/cncr.20003

[26] Lai, H.C., Sun, C.A., Yu, M.H., et al. (1999) Favorable Clinical Outcome of Cervical Cancers Infected with Human Papilloma Virus Type 58 and Related Types. International Journal of Cancer, 84, 553-557. https://doi.org/10.1002/(SICI)1097-0215(19991222)84:6<553::AID-IJC2>3.0.CO;2-4

[27] Pilch, H., Gunzel, S., Schaffer, U., et al. (2001) Human Papillomavirus (HPV) DNA in Primary Cervical Cancer and in Cancer Free Pelvic Lymph Nodes-Correlation with Clinico-Pathological Parameters and Prognostic Significance. Zentralblatt für Gynäkologie, 123, 91-101. https://doi.org/10.1055/s-2001-12411

[28] Harima, Y., Sawada, S., Nagata, K., Sougawa, M and Ohnishi, T. (2002) Human Papilloma Virus (HPV) DNA Associated with Prognosis of Cervical Cancer after Radiotherapy. International Journal of Radiation Oncology ${ }^{\star}$ Biology ${ }^{\star}$ Physics, 52, 1345-1351. https://doi.org/10.1016/S0360-3016(01)02796-1

[29] Wang, C.-C., Lai, C.-H., Huang, H.-J., et al. (2010) Clinical Effect of Human Papillomavirus Genotypes in Patients with Cervical Cancer Undergoing Primary Radiotherapy. International Journal of Radiation Oncology ${ }^{\star}$ Biology ${ }^{\star}$ Physics, 78, 1111-1120. https://doi.org/10.1016/j.ijrobp.2009.09.021

[30] Hang, D.R., Islam, S.E., Sharma, K.H., Kuo, S.W., Zhang, C.Z. and Wang, J.J. (2014) Annealing Effects on the Optical and Morphological Properties of ZnO Nanorods on AZO Substrate by Using Aqueous Solution Method at Low Temperature. Nanoscale Research Letters, 9, 632. https://doi.org/10.1186/1556-276X-9-632

[31] Dem, A., Dieng, M.M., Traoré, B., Gaye, M., Diop, M. and Touré, P. (2008) Les carcinomes épidermoïdes du col utérin à l'Institut du cancer de Dakar. Cahiers d'Etudes et de Recherches Francophones/ Santé, 18, 31-33.

[32] Lai, C.H., Chou, H.H., Chang, C.J., Wang, C.C., Hsueh, S., Huang, Y.T., et al. (2013) Clinical Implications of Human Papillomavirus Genotype in Cervical Adenoadenosquamous Carcinoma. European Journal of Cancer, 49, 633-641. https://doi.org/10.1016/j.ejca.2012.09.008

[33] Hang, D., Jia, M.Q., Ma, H.X., Zhou, J., Feng, X.S. and Lyu, Z.Y. (2017) Independent Prognostic Role of Human Papillomavirus Genotype in Cervical Cancer. BMC Infectious Diseases, 17, 391. https://doi.org/10.1186/s12879-017-2465-y

[34] Wang, S.H., Wei, H., Wang, N., Zhang, S.L. and Zhang, Y. (2012) The Prevalence and Role of Human Papillomavirus Genotypes in Primary Cervical Screening in the Northeast of China. BMC Cancer, 12, 160.

https://doi.org/10.1186/1471-2407-12-160

[35] Lai, C.H., Chao, A., Chang, C.J., Huang, C.C., Wang, L.C., Hsueh, S., et al. (2011) Age Factor and Implication of Human Papillomavirus Type-Specific Prevalence in Women with Normal Cervical Cytology. Epidemiology \& Infection, 140, 466-473. 